\title{
Investimento privado: uma análise empírica para o Brasil ${ }^{1}$
}

\author{
Viviane Luporini ${ }^{2}$ \\ Joana Alves ${ }^{3}$
}

\begin{abstract}
Resumo
O presente estudo identifica os determinantes do investimento privado no Brasil para o período compreendido entre 1970 e 2005. O artigo apresenta as principais teorias de investimento, os desenvolvimentos recentes e as principais aplicações para os dados brasileiros. Os resultados indicam que aumentos na renda e na atividade econômica influenciam positivamente o investimento do setor privado no Brasil. A redução no volume de crédito e a existência de instabilidades políticas e econômicas mostraram-se prejudiciais ao investimento privado no período analisado. A implementação de políticas públicas que possam garantir a estabilidade econômica e a credibilidade dos agentes, assim como aumentos na oferta de crédito, podem elevar o nível de investimento privado no Brasil.
\end{abstract}

Palavras-chave: Capital; Investimento; Capacidade; Aplicação; Brasil.

\section{Abstract \\ Private investment: an empirical analysis for Brazil}

This study identifies the determinants of private investment in Brazil over the period of 1970 to 2005. The paper presents the main investment theories, and recent developments of these theories, as well as how they can be applied to Brazilian data. The results indicate that increases in income and economic activity have positively influenced private sector investment in Brazil. The reduction in credit volume and the existence of political and economic instabilities are shown as being harmful to private investment in the analyzed period. The implementation of public policies that can guarantee economic stability and improve the government's credibility, along with increases in credit offer, may boost private investment in Brazil.

Key words: Capital; Investment; Capacity; Application; Brazil.

JEL E22.

\section{Introdução}

O investimento em capital fixo pode ser considerado um dos principais componentes na determinação do produto, emprego e renda da economia de um país, pois promove o aumento da capacidade produtiva e a expansão do nível de atividade. No Brasil, uma média de $89 \%$ da formação bruta de capital fixo nos

(1) Trabalho recebido em setembro de 2007 e aprovado em agosto de 2009.

(2) Professora do Instituto de Economia da Universidade Federal do Rio de Janeiro (UFRJ), Rio de Janeiro, RJ, Brasil. E-mail: viviane.luporini@ie.ufrj.br.

(3) Mestre em Economia pela Universidade Federal Fluminense (UFF), Niterói, RJ, Brasil. E-mail: joanadoalves@terra.com.br. 
últimos dez anos foi realizada pelo setor privado, o que corresponde a aproximadamente $15 \%$ do Produto Interno Bruto (PIB) brasileiro nesse período. O ritmo e o padrão dos investimentos em capital fixo são tópicos centrais para o entendimento da atividade econômica, e a volatilidade destes contribui fortemente para as flutuações agregadas. Sob esta perspectiva, modelos teóricos e resultados empíricos relacionados ao investimento estimulam e fornecem informação para discussões de políticas econômicas.

Dentre os trabalhos empíricos recentes que procuram identificar os determinantes do investimento privado no Brasil, os estudos de Melo e Rodrigues Júnior (1998) e Ribeiro e Teixeira (2001) estão entre os mais frequentemente citados na literatura. Para a especificação de uma equação de investimento, os autores combinam diferentes teorias - como o modelo do acelerador, o modelo neoclássico, os efeitos da restrição de crédito, do investimento público e da instabilidade macroeconômica - e analisam o impacto dessas variáveis sobre o nível de investimento privado. Os resultados sugerem efeitos positivos da demanda agregada sobre o investimento, relação negativa entre investimento privado e público no curto prazo, influência positiva da disponibilidade de crédito e impacto adverso da instabilidade econômica sobre o investimento do setor privado no Brasil.

O presente estudo realiza uma análise empírica sobre os determinantes do investimento privado no Brasil, no período de 1970 a 2005, com o objetivo de identificar as variáveis macroeconômicas relevantes para explicar as flutuações da formação bruta de capital fixo do setor privado no país, assim como verificar se fatores específicos às economias em desenvolvimento afetaram o investimento privado no país durante o período estudado.

Este artigo diferencia-se dos trabalhos existentes sobre os determinantes do investimento privado no Brasil por, ao menos, duas razões. Primeiro, o estudo utiliza uma nova base de dados do Novo Sistema de Contas Nacionais do Instituto Brasileiro de Geografia e Estatística (SCN/IBGE - Referência 2000), divulgada recentemente (maio/2007). A utilização desses novos dados possibilitou a extensão do período de análise em relação aos demais trabalhos presentes na literatura, além de uma possível revisão dos resultados obtidos por outros autores. Em segundo lugar, considerando o número de observações e as características econométricas dos dados utilizados, o presente artigo utiliza modelos autorregressivos de defasagens distribuídas (ARDL) para estimar os efeitos de variáveis tradicionalmente consideradas importantes para o investimento privado.

O artigo é composto de quatro seções, além desta introdução. A primeira e a segunda seções apresentam, respectivamente, um breve panorama das principais teorias de investimento, enfatizando as implicações empíricas passíveis de serem 
estimadas e os principais resultados empíricos obtidos pela literatura aplicada ao caso brasileiro. As seções três e quatro apresentam os dados utilizados nas estimações e a os resultados econométricos obtidos. Finalmente, a última seção conclui o trabalho.

\section{Determinantes do investimento: um panorama teórico}

As principais teorias dos determinantes do investimento relacionam os custos e benefícios da aquisição de unidades adicionais de capital fixo. Na teoria Keynesiana, o empresário toma a decisão de investir com base na comparação entre a taxa de retorno esperada do investimento, a chamada eficiência marginal do capital, e o custo de oportunidade do capital a ser investido, que é dado pela taxa para obtenção de fundos ou de aplicação de recursos no mercado financeiro (taxa de juros). As flutuações do investimento e, por conseguinte, da demanda agregada são resultantes da escolha intertemporal do empresário entre a retenção de ativos de liquidez universal (moeda), e a de empreender a criação de ativos de liquidez específica (investimento), decisão que é dada pela comparação entre a taxa de juros ("recompensa" pela renúncia à liquidez) e a eficiência marginal do capital (retorno esperado para o investimento), sob condições de incerteza.

Embora originário do início do século XX (Clark, 1917), o chamado modelo do acelerador tornou-se popular durante a década de 1960 ao estabelecer uma relação fixa entre o estoque de capital e o produto (Clark, 1944; Koyck, 1954). Assumindo-se que o estoque de capital desejado ou ideal mantém-se proporcional ao nível de produto, o investimento líquido seria então proporcional à variação do produto. ${ }^{4}$ A ausência de preços, em particular o custo do capital como um dos componentes explicativos das equações de investimento nos modelos anteriores levou, no entanto, ao surgimento da teoria neoclássica do investimento (Jorgenson, 1963). ${ }^{5} \mathrm{O}$ estoque desejado do capital fixo seria então uma função do nível do produto e do custo de uso do capital, o qual, segundo Servén e Solimano (1993a), seria, por sua vez, uma função dos preços dos bens de capital, dos custos financeiros do capital líquidos de impostos, da taxa de impostos sobre os lucros e do valor descontado da taxa planejada de depreciação.

A necessidade de explorar os elementos dinâmicos e expectacionais intrínsecos ao processo do investimento levou ao surgimento de modelos teóricos

(4) A teoria do acelerador, em várias versões, já pode ser encontrada em Harrod (1939), "An essay to dynamic theory", assim como em Samuelson (1939) e Hicks (1950).

(5) Segundo Chirinko (1993), antes da "Revolução Neoclássica" não existiu nenhum estudo rigoroso que investigasse os determinantes do investimento, especialmente os efeitos dos preços relativos sobre a aquisição de bens de capital. Para Chirinko (1993), a Teoria Geral de Keynes (1936) apenas introduziu informalmente os efeitos dos preços e choques da economia sobre o investimento, onde os benefícios e custos de aquisição de capital eram relacionados à eficiência marginal do capital e taxa de juros, respectivamente. 
que enfatizassem aspectos intertemporais da tecnologia, dos custos de ajustamento e das expectativas no contexto do problema de otimização da firma. A teoria $q$ do investimento, introduzida ainda na obra de Keynes (1936) e revitalizada e elaborada por Tobin (1969), pode ser pensada como uma primeira tentativa de modelar a dinâmica do investimento a partir de valores expectacionais. De acordo com a teoria $q$, as despesas de investimento relacionam-se positivamente com a razão entre o valor de mercado da firma e o custo de reposição do estoque de capital existente. $\mathrm{O}$ valor $q$ concentra, portanto, as informações relevantes sobre as condições futuras de oferta e demanda que afetam o investimento. Dados os custos de ajustamento ao nível desejado de capital, a taxa de investimento deveria ser determinada exclusivamente pelo valor contemporâneo de $q$ e choques inesperados (Caballero, 1999). Empiricamente, no entanto, outras variáveis (como produto e liquidez) têm se mostrado relevantes e o desempenho da teoria $q$ pode ser considerado insatisfatório tanto em termos da significância da variável utilizada para expressar $q$ quanto no ajustamento geral da equação de investimento (Chirinko, 1993).

No contexto de modelos neoclássicos, originalmente proposto por Jorgenson (1963, 1971), a equação de investimento tem sido derivada a partir de um problema de otimização da firma, a qual escolhe os insumos de produção (capital e trabalho) competitivamente de forma a maximizar o valor descontado do fluxo esperado de caixa. Assume-se que os incrementos do estoque de capital estão sujeitos a custos de ajustamento, os quais crescem a uma taxa crescente na taxa de investimento e são avaliados em termos de perda de produto. ${ }^{6}$ Do problema de otimização resulta que o estoque de capital ótimo equaciona, no tempo corrente, o benefício marginal (medido pelo chamado "preço-sombra" do capital) e o custo marginal (representado pelo custo do capital propriamente dito e pelos chamados sunk-costs ou "custos afundados") do investimento. Dessa forma, sempre que há uma discrepância entre o preço-sombra esperado do capital e seu preço relativo (ajustado para impostos), a firma tem um incentivo para investir. Nesse caso, o investimento ocorre de acordo com os custos de ajustamento ao estoque de capital desejado: quanto mais rapidamente esses custos crescem com o nível do investimento, mais lenta é a resposta da firma à discrepância entre o preço-sombra esperado e o preço relativo do capital. Do ponto de vista empírico, o problema crítico é associar o preço-sombra do capital, que não pode ser observado, a variáveis que possam ser diretamente medidas. ${ }^{7}$

(6) Os modelos baseiam-se na hipótese de custos de ajustamento convexos que permite ajustes graduais ao estoque de capital desejado pela firma. Boucekkine e Cruz (2006) apresentam uma excelente discussão sobre a hipótese de custos não-convexos na geração de ajustes infrequentes no estoque de capital das firmas.

(7) O preço-sombra do capital pode ser definido como o valor presente esperado descontado da rentabilidade marginal do capital, a qual pode ser representada pelos lucros ou vendas por unidade de capital. 
Outras questões que têm sido apresentadas pela literatura teórica (e empírica) sobre o investimento relacionam-se às restrições financeiras, ao papel do investimento público, à instabilidade do ambiente econômico e às condições externas.

Para que a realização do investimento em bens de capital possa ser concretizada, as firmas necessitam de fontes de financiamento que possibilitem a efetivação do investimento. No entanto, a existência de assimetria de informação, seleção adversa e efeitos de incentivos podem fazer com que os credores preferiram racionar crédito elevando o custo do financiamento externo à firma (Stiglitz; Weiss, 1981). O problema do racionamento do crédito mostra-se ainda mais relevante para as economias em desenvolvimento. De acordo com Ronci (1988), a quantidade de recursos financeiros disponíveis nos países em desenvolvimento seria mais importante que seu próprio custo, já que uma parcela significativa das firmas se depara com racionamento de crédito, e o impacto sobre o investimento privado é amplificado pela existência de uma fraca estrutura do mercado de capitais (Rama, 1993). Empiricamente, o efeito de restrições de crédito sobre o investimento é verificado pela relevância (ou não) de uma medida de liquidez, como, por exemplo, o fluxo de caixa da firma (Fazzari; Hubbard; Petersen, 1988).

No que tange ao papel do investimento público, este pode afetar positiva ou negativamente o investimento privado. Um maior nível de investimento público, que gere melhorias na infraestrutura e no sistema de serviços (estradas, portos, meios de comunicação, por exemplo) e aumento na produtividade geral da economia, pode gerar externalidades positivas estimulando o investimento privado, principalmente em países com falta de infraestrutura ou com baixa provisão de bens públicos. ${ }^{8}$ Além disso, o investimento público também pode atuar de maneira contra-cíclica, aumentando a demanda por insumos e serviços do setor privado. Neste caso, a acumulação de capital público exerce um papel complementar ao investimento privado. Por outro lado, um aumento nos gastos públicos que gerem déficits fiscais não sustentáveis pode reduzir o investimento privado (efeito crowding-out). Em países desenvolvidos, o efeito deslocamento do investimento privado dá-se primordialmente via elevação das taxas de juros. Nas economias em desenvolvimento que enfrentam restrições financeiras, além de aumentos na taxa de juros, o setor público acaba utilizando recursos físicos e financeiros que, de outra forma, estariam disponíveis para o setor privado. Uma menor disponibilidade de crédito, por exemplo, acaba reduzindo o investimento da economia, pelo menos no curto prazo. A formação de capital por parte do governo

(8) Para resultados empíricos que envolvam essa discussão no período de 1970-2000, ver Cândido Júnior (2006).

Economia e Sociedade, Campinas, v. 19, n. 3 (40), p. 449-475, dez. 2010. 
também pode produzir bens que competem com aqueles produzidos pelo setor privado.

O caráter irreversível das decisões individuais de investimento gera os chamados sunk costs já mencionados, os quais podem ser exacerbados pelas condições macroeconômicas. Bernanke (1983), por exemplo, afirma que em projetos individuais irreversíveis os agentes devem tomar decisões de investimento que levem em conta o "trade-off" entre retornos extras, por assumir o compromisso cedo e o ganho pela espera de maiores informações para posterior tomada de decisão. Assim, a estabilidade nos ambientes econômico e institucional é fundamental para viabilizar um horizonte de planejamento necessário aos investimentos. Finalmente, as condições externas de um país podem afetar as decisões de investimento privado por diversas razões. A existência de compromissos externos - tais como o pagamento de dívida externa - pode afetar o nível de investimento das economias, principalmente no caso de países em desenvolvimento, já que requer a transferência de recursos para o exterior que, sob condições de financiamento limitado, leva à redução de recursos para o investimento. A existência de compromissos externos pendentes torna os países mais vulneráveis a crises externas, e, além disso, estes ficam expostos às consequências de políticas de ajustamento conduzidas pelos governos para superação das crises econômicas. No que tange à taxa de câmbio, Servén e Solimano (1993) concluem que o efeito de mudanças na taxa real de câmbio sobre o investimento privado é complexo, e seu mecanismo pode ser entendido pela chamada "dinâmica J"; ou seja, uma depreciação cambial faz com que o investimento inicialmente decresça, em função do aumento dos preços de bens de capital importados, o que reduz a formação bruta de capital. Com o passar do tempo, a depreciação estimula o aumento das exportações e o investimento, inicialmente no setor de bens comercializáveis e posteriormente nos demais, com a elevação do produto. Já a variabilidade da taxa real de câmbio, como medida de incerteza, pode exercer um efeito adverso significativo na formação de capital.

\section{Evidências empíricas: os modelos aplicados aos dados brasileiros}

Alguns dos primeiros trabalhos empíricos desenvolvidos sobre os determinantes do investimento privado que consideravam o Brasil surgiram nas décadas de 1970 e 1980. As pesquisas contemplavam, de forma básica, variáveis que teoricamente pudessem refletir as condições da demanda agregada existentes nas economias dos países em estudo (ver Tabela A.1, no Apêndice). Foram utilizados dados de produto e suas taxas de crescimento, produção do setor privado, utilização de capacidade instalada, entre outros. Os resultados indicam que, de maneira geral, a demanda agregada aparece como uma importante variável explicativa do investimento, com coeficientes positivos e significantes, enquanto 
que variáveis de custo do capital, quando contempladas, mostraram-se pouco relevantes. Uma exceção pode ser feita ao trabalho de Reis et al. (1999), no qual a taxa de juros foi positiva e estatisticamente significativa.

O estudo de Dailami (1987), um dos primeiros a investigar empiricamente os determinantes do investimento no Brasil, utilizou dados macroeconômicos anuais para a variação do produto interno bruto - uma medida de preço dos fatores, notadamente variações no custo de utilização do capital e no salário real, e uma medida de instabilidade econômica medida pela volatilidade da bolsa de valores. O período estudado compreendeu os anos de 1958 a 1984 e o autor encontra efeitos positivos da demanda agregada e da variação do salário real, e efeitos negativos do custo de utilização do capital e da instabilidade econômica sobre o investimento privado. Studart (1992), Jacinto e Ribeiro (1998) e Ribeiro e Teixeira (2001) incluem variáveis financeiras, como a disponibilidade de crédito nos estudos empíricos, encontrando impactos positivos sobre diversas medidas de investimento. Existe, no entanto, a possibilidade de causalidade reversa, isto é, as decisões de investimento terem determinado a expansão do crédito (Rama, 1993).

Os trabalhos de Studart (1992), Rocha e Teixeira (1996), Jacinto e Ribeiro (1998) e Cruz e Teixeira (1999), dentre outros, focam especificamente o impacto do investimento público sobre a formação bruta de capital fixo do setor privado, além dos estudos de Ronci (1991), Melo e Rodrigues Jr. (1998) e, mais recentemente, Santos e Pires (2007), que inserem medidas de investimento público em seus modelos agregados como uma variável de controle. Alguns resultados indicam complementaridade entre investimento público e privado, notadamente Ribeiro e Teixeira (2001), enquanto outros indicam um efeito deslocamento, como, por exemplo, Santos e Pires (2007).

No que tange à instabilidade econômica, diversos indicadores foram utilizados nos trabalhos empíricos, tais como desvios do produto de sua tendência de longo-prazo, a volatilidade da bolsa de valores, a variabilidade da taxa de inflação e/ou do câmbio e a relação dívida/PIB, com resultados negativos sobre o investimento privado (Dailami, 1987; Cardoso, 1992; Studart, 1992; Jacinto; Ribeiro, 1998; Melo; Rodrigues Jr., 1998 e Ribeiro; Teixeira, 2001).

Finalmente, Cardoso (1992) utiliza a relação dívida externa e exportações para averiguar os efeitos das condições externas sobre o investimento privado no Brasil e outros países da América Latina, confirmando o resultado negativo já encontrado por outros estudos. Mais recentemente, Ribeiro e Teixeira (2001) investigam a relação entre taxa de câmbio e investimento privado. Os resultados indicam que o câmbio afetou negativa e significativamente o investimento privado no período analisado, a saber, 1956 a 1996. 
Viviane Luporini / Joana Alves

\section{Determinantes do Investimento: novas evidências}

O presente trabalho utiliza séries macroeconômicas divulgadas pelo Instituto de Pesquisas Aplicadas (Ipeadata) que foram encadeadas de forma a oferecer observações anuais metodologicamente consistentes para as séries de interesse, viabilizando novas estimações dos determinantes do investimento para o Brasil.

Para analisar empiricamente os diversos modelos teóricos de investimento são utilizadas séries macroeconômicas da formação bruta de capital fixo privado (IP), do produto interno bruto (Y) e utilização da capacidade instalada (UTCAP) para refletir as condições de demanda agregada e representar o modelo do acelerador, e taxa de juros real (R) utilizada como medida do custo de utilização do capital, como sugerido pelas várias versões do modelo neoclássico de decisão da firma. As operações de crédito do sistema financeiro (CRED) são inseridas para testar a existência de restrições de crédito na economia brasileira, e a formação bruta de capital fixo da administração pública (IG) é usada para identificar a relação entre investimento público e privado no Brasil. Utiliza-se uma combinação das variáveis de inflação, juros e câmbio na construção de um indicador de instabilidade para se avaliar o impacto da instabilidade econômica sobre o investimento privado. Medidas de endividamento externo (EE) e taxa de câmbio (E) são úteis para investigar a influência de mudanças nas condições externas sobre o investimento privado no Brasil.

Para as variáveis IP e IG, as séries históricas da formação bruta de capital fixo (FBCF) de Empresas e Famílias e da FBCF da Administração Pública (governos federal, estadual e municipal) são utilizadas. Essas séries representam acréscimos ao estoque de bens duráveis destinados ao uso das unidades produtivas, privadas e públicas, realizados em cada ano, visando ao aumento da capacidade produtiva do país. Nas Estatísticas do Século XX, o IBGE disponibiliza dados macroeconômicos desde 1901. No entanto, os dados para a formação bruta de capital fixo até o ano de 1970 são estimativas (Morandi; Reis, 2004). Os dados referentes à formação bruta de capital fixo público, disponíveis a partir de 1947, referem-se somente à construção (não inclui máquinas e equipamentos), sendo que a série FBCF Pública e Privada foi descontinuada pelo IBGE a partir de 2003. O Instituto de Pesquisas Aplicadas (Ipea) fornece, a partir das informações das Contas Nacionais do IBGE (Consolidadas, Referência 1985 e 2000) dados encadeados para o período de 1970 a 2005 para as variáveis FBCF de Empresas e Famílias e FBCF da Administração Pública. As taxas de investimento privado e público baseadas nesses dados e utilizadas nas nossas estimações são apresentadas no Gráfico 1. 
Gráfico 1

Taxas de investimento privado e público

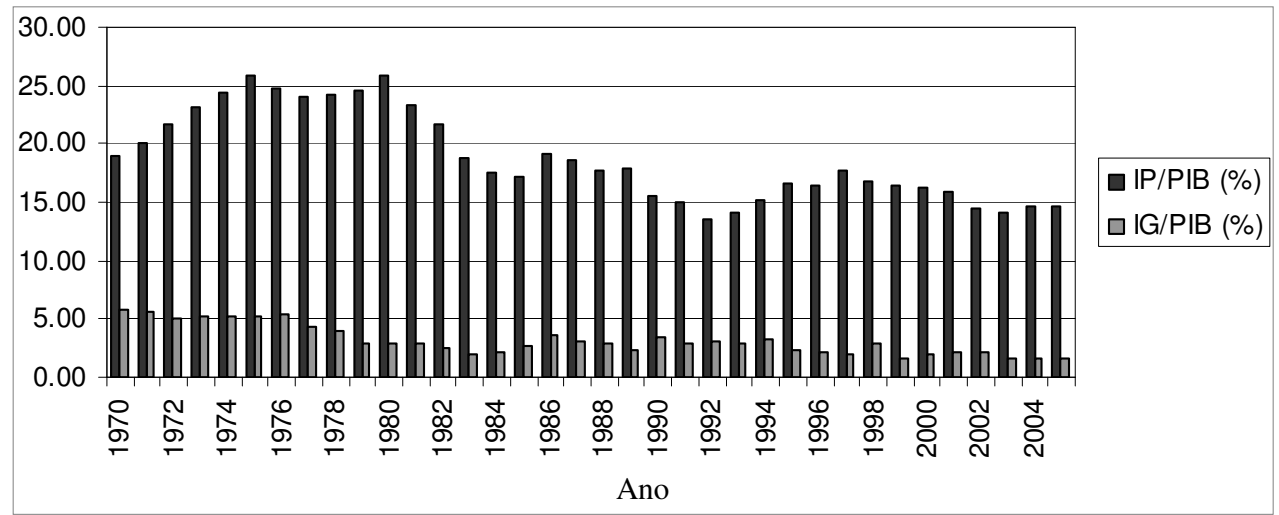

Convém notar que a mensuração da FBCF, seja das empresas e famílias, seja da administração pública, não é algo trivial, como mostram os estudos de Morandi e Reis (2004) e Gobetti (2006). Este último, em particular, mostra que os valores disponíveis nos balanços oficiais do IBGE e os estimados pelo Ipea para a FBCF da Administração Pública possuem um viés de superestimativa devido à discrepância entre os valores de investimento empenhados no orçamento do governo e os efetivamente liquidados. No âmbito federal, o autor detecta uma superestimativa da ordem de $17,7 \%$ entre 1999 e 2005, sendo a maior distorção $(42,5 \%)$ observada em $2004 .^{9}$

Para caracterizar o modelo do acelerador, são utilizados dados referentes ao Produto Interno Bruto (PIB), ${ }^{10}$ também compilados pelo IBGE e disponibilizados pelo Ipeadata, e o grau de utilização da capacidade instalada da indústria brasileira (UTCAP), uma das medidas do grau de "aquecimento" da economia. A série selecionada é a Utilização da Capacidade Instalada - Geral, divulgada pela Fundação Getúlio Vargas (FGV). Como a série possui frequência trimestral, os dados utilizados são formados pela média anual da utilização da capacidade.

A teoria neoclássica do investimento sugere que o custo de uso do capital é uma das variáveis relevantes nas decisões de investimento, a qual é composta

(9) Em um novo estudo, Gobetti (2009) apresenta valores para a FBCF da Administração Pública que, segundo o autor, podem ser pensados como "uma espécie de teto para a verdadeira FBCF da Administração Pública" (p. 6). Assim, os dados do IBGE ou do Ipeadata que ultrapassam os "tetos" estariam superestimando o real valor dos investimentos públicos.

(10) Em 2006, o IBGE divulgou uma revisão do PIB para 2005 com base em novas taxas de crescimento dos setores agropecuário, indústria e serviços, evidenciando uma maior participação relativa deste último. Os dados utilizados aqui não contemplam esse novo valor do PIB para 2005, uma vez que a alteração metodológica não foi implementada para toda a série disponibilizada. 
pelo preço real do capital, custos de depreciação, pela taxa de variação do preço real do capital e pela taxa de juros real, líquidos de impostos. Do ponto de vista empírico, são grandes as dificuldades para se obter uma boa medida do custo de uso do capital. Ainda que seja uma medida incompleta do custo de uso do capital, é comum a utilização de uma taxa de juros real na análise empírica. Nesse artigo, são utilizadas as taxas de juros nominais dos Certificados de Depósito Bancário (CDB), disponibilizadas pelo Banco Central do Brasil (BCB). As taxas praticadas nos CDBs podem ser consideradas uma proxy para o custo do financiamento já que seguem os custos de captação privada, os quais baseiam-se, em geral, nas taxas pagas pelo Certificado de Depósito Interbancário (CDI), acrescidas de um spread. Além disso, os CDBs seguem a taxa básica de juros, a Selic.

Para analisar os possíveis efeitos das restrições ao crédito sobre o desempenho do investimento privado brasileiro, são utilizados os dados de Operações de Crédito do Sistema Financeiro - Setor Privado, fornecida pelos boletins da Seção Moeda e Crédito, do BCB. Convém notar que as operações de crédito consideradas aqui incluem não somente operações de crédito destinadas à formação de capital fixo pelas empresas, como também operações de crédito ao consumidor e crédito à produção (capital de giro e financiamento de vendas), que afetariam as decisões de investimento somente indiretamente.

Finalmente, utilizamos a taxa de câmbio real e uma proxy para a existência de restrições externas, representadas pela razão dívida externa/PIB, para averiguar o impacto das condições externas sobre o investimento privado no Brasil.

Concretamente, as variáveis utilizadas nas estimações são:

IP = Investimento Privado, série Capital Fixo- Formação Bruta (FBCF) Empresas e Famílias, em milhões de Reais de 2005, utilizando-se o deflator implícito da FBCF. Ipeadata, a partir de IBGE/SCN, Contas Consolidadas, Referência 1985 e 2000, Anual - SCN_FBKFPN.

$\mathrm{PIB}=$ Produto Interno Bruto: série Produto Interno Bruto (IBGE), em milhões de Reais de 2005; utilizou-se o deflator implícito do PIB, SCN/IBGE Referência 2000. Ipeadata, a partir de IBGE/SCN, Contas Consolidadas, Referência 1985 e 2000, Anual.

UTCAP = Nível de Utilização de Capacidade (\%): média das observações trimestrais da série Utilização de Capacidade Instalada - Geral, FGV. Baseia-se fundamentalmente no setor industrial.

$\mathrm{R}=$ Taxa de Juro Real (\%): taxa de juro nominal dos Certificados de Depósito Bancário (CDB), deflacionada pelo Índice Geral de Preços (IGP-DI) e anualizada, Banco Central do Brasil. 
CRED = Volume de Crédito: série Operações de crédito do sistema financeiro - setor privado - BCB Boletim/Moeda, deflacionada pelo Índice Geral de Preços (IGP-DI), milhões de Reais de 2005, Banco Central do Brasil.

IG = Investimento Público: série Capital Fixo - Formação Bruta Administração Pública, em milhões de Reais de 2005, utilizando-se o deflator implícito da FBCF. Ipeadata, a partir de IBGE/SCN, Contas Consolidadas, Referência 1985 e IBGE/SCN 2000 Anual - SCN_FBKFGN.

$\mathrm{EE}=$ Restrição Externa, Proxy utilizada é a série Serviço da dívida/PIB (\%) - anual - DEPEC-BCB, Banco Central do Brasil.

E = Taxa de câmbio Real: Taxa de câmbio - R\$ / US\$ (comercial - venda média, R\$) - BCB Boletim/BP, Banco Central do Brasil, multiplicada pela razão $P^{E U A} / P^{B R}$, onde $P^{E U A}$ é o Índice de Preços ao Consumidor para o Estados Unidos (IPC - média $2000=100$ - FMI/IFS - Internacional) e $P^{B R}$ é o Índice Geral de Preços para o Brasil (IGP-DI ago. $1994=100-$ FGV/Conj. Econômica); ambos os índices de preços foram transformados para base $2005=100$.

INST $=$ Indicador de Instabilidade Econômica, INST $=(1+P)+\Delta R+\Delta E$, onde $P$ é a taxa de inflação $(e m \%) / 100$, medida pela variação do Índice Geral de Preços - Disponibilidade Interna (IGP-DI), divulgado pela Fundação Getúlio Vargas (FGV); R é a taxa de juro real (definida acima) e E é taxa de câmbio (R\$/US\$), ambas divulgadas pelo Banco Central do Brasil.

\section{Análise econométrica}

Para a análise econométrica, todas as variáveis, com exceção da taxa de juros, foram log-linearizadas utilizando-se o logaritmo natural e, quando apropriado, calculadas a preços constantes de 2005. Os dados utilizados nas estimações estão apresentados no Apêndice.

Como as séries utilizadas nas estimações das equações de investimento são séries temporais, assume-se que essas séries são variáveis aleatórias ordenadas no tempo. Os métodos usuais de estimação e inferência supõem que essas variáveis são estacionárias. A não-estacionaridade de um processo estocástico é devida à existência de raiz unitária ou tendência estocástica no processo autorregressivo que gera a variável, e testes sobre a hipótese de raiz unitária podem auxiliar na avaliação da presença (ou ausência) de estacionaridade nas variáveis utilizadas nas estimações.

As séries foram submetidas aos testes de raiz unitária Dickey e Fuller Aumentado (ADF) (Dickey; Fuller, 1981), Phillips-Perron (PP) (Perron, 1989), 
DF-GLS (Elliott; Rothemberg; Stock, 1996) e KPSS (Kwiatkowski et al., 1992). O número de defasagens em cada caso foi determinado pelo critério de informação de Schwarz (SC). Os resultados estão sintetizados na Tabela 1.

A análise dos resultados indica que as séries para juros reais (R), investimento público (IG) e taxa de câmbio real (E) podem ser consideradas estacionárias. As séries integradas de primeira ordem, em nível I(1), precisam ser diferenciadas para que se tornem estacionárias. Para algumas variáveis, no entanto, os testes apresentam resultados contraditórios (variáveis I(0) ou I(1)). Uma possível explicação para esse fato é que os testes de estacionaridade são sensíveis à especificação e à unidade de medida das variáveis, dificultando a análise dos resultados. Além disso, o baixo poder dos testes dificultam o discernimento entre séries estocásticas e de alta dependência. Analisando-se essas variáveis em primeira diferença, observa-se que se tornam estacionárias, ou seja, não apresentam raiz unitária. Quer dizer que, dentre as séries de interesse, há séries estacionárias em nível e séries que se tornam estacionárias na primeira diferença. Dadas essas características, as equações de investimento foram estimadas pela metodologia de Mínimos Quadrados Ordinários. Alguns estudos dos determinantes do investimento apresentados na literatura utilizam a técnica de cointegração a partir de um sistema de vetores autorregressivos (VAR) [ver Tabela A.1 no Apêndice]. A análise de cointegração pressupõe variáveis integradas de mesma ordem e as propriedades estatísticas do vetor cointegrante são derivadas assintoticamente. Como indicam os testes de raiz unitária, as variáveis de interesse possuem ordem de integração distintas inviabilizando a análise de cointegração. Além disso, as observações anuais para o período 1970 a 2005 totalizam o número de 36. Do ponto de vista econométrico, esse número caracteriza a amostra como de tamanho pequeno. O estimador de Mínimos Quadrados Ordinários é um dos poucos estimadores cujas propriedades para pequenas amostras estão solidamente estabelecidas na literatura especializada.

As equações de investimento são então estimadas por Mínimos Quadrados Ordinários, utilizando-se os dados anuais para o período 1970 a 2005, a partir da especificação de um modelo Autorregressivo com Defasagens Distribuídas (ARDL). Partindo-se de um modelo geral de defasagens para um específico, este tipo de modelo permite a inclusão de valores presentes e passados dos regressores, assim como valores passados da variável dependente revelando-se particularmente adequado ao estudo dos determinantes do investimento, uma vez que o estoque de capital é o resultado acumulado de decisões passadas de investimento. 
Tabela 1

Testes de Raiz Unitária

\begin{tabular}{|c|c|c|c|c|c|c|c|c|c|c|}
\hline \multicolumn{6}{|c|}{ Variáveis em Nível } & \multicolumn{5}{|c|}{ Variáveis em Primeira Diferença } \\
\hline Séries & $\mathrm{ADF}$ & PP & DF-GLS & KPSS* & $\begin{array}{l}\text { Ordem de } \\
\text { Integração }\end{array}$ & Séries & $\mathrm{ADF}$ & PP & DF-GLS & $\begin{array}{l}\text { Ordem de } \\
\text { Integração }\end{array}$ \\
\hline $\ln$ IP & $-3.811931^{b}-$ & $-3.829081^{a}$ & -2.017789 & 0.109698 & $\mathrm{I}(0)$ ou $\mathrm{I}(1)$ & $\mathrm{D} \ln \mathrm{IP}$ & $-3.817029^{a}$ & $-3.544543^{a}$ & $-3.873428^{a}$ & $\mathrm{I}(0)$ \\
\hline $\ln Y$ & $-3.655033^{b}-$ & $-7.715687^{a}$ & -1.798307 & $0.179265^{b}$ & $\mathrm{I}(0)$ ou $\mathrm{I}(1)$ & $D \ln Y$ & $-3.007728^{b}$ & $-4.001149^{b}$ & $-4.093845^{a}$ & $\mathrm{I}(0)$ \\
\hline ln UTCAP & -1.864792 & -1.951598 & -1.784280 & $0.167853^{b}$ & $\mathrm{I}(1)$ & D $\ln U T C A P$ & $-5.453528^{a}$ & $-5.440779^{a}$ & $-5.528153^{a}$ & $\mathrm{I}(0)$ \\
\hline $\mathrm{R}$ & $-4.204895^{b}-$ & $-4.318802^{a}$ & $-4.266882^{a}$ & 0.106374 & $\mathrm{I}(0)$ & & & & & \\
\hline ln CRED & $-3.655118^{a}$ & -3.34908 & -1.219629 & 0.106054 & $\mathrm{I}(0)$ ou $\mathrm{I}(1)$ & $\mathrm{D} \ln \mathrm{CRED}$ & $-2.990363^{a}$ & $-2.805757^{a}$ & $-2.514794^{b}$ & $\mathrm{I}(0)$ \\
\hline $\ln \mathrm{IG}$ & $3.479176^{b}$ & $-3.472529^{b}$ & $-3.140538^{b}$ & 0.082093 & $\mathrm{I}(0)$ & & & & & \\
\hline ln INST & $-7.557839^{a}$ & $-8.765419^{a}$ & $-7.792454^{\mathrm{a}} \mathrm{C}$ & $0.368666^{\mathrm{a}}$ & $\mathrm{I}(0)$ ou $\mathrm{I}(1)$ & $\mathrm{D} \ln \mathrm{INST}$ & $-5.655597^{\mathrm{a}}$ & $-12.83602^{\mathrm{a}}$ & $-5.886412^{a}$ & $\mathrm{I}(0)$ \\
\hline $\mathrm{EE}$ & -2.180199 & -2.251919 & -1.771673 & 0.302643 & $\mathrm{I}(1)$ & D EE & $-6.543213^{a}$ & $-6.518579^{a}$ & $-6.652104^{a}$ & $\mathrm{I}(0)$ \\
\hline $\ln E$ & $-2.422707^{c}$ & -2.012998 & $-2.472991^{b}$ & 0.115811 & $\mathrm{I}(0)$ & & & & & \\
\hline
\end{tabular}

(*) A hipótese nula do teste KPSS é estacionaridade.

(a) Indica rejeição da hipótese nula ao nível de $1 \%$ de significância.

(b) Indica rejeição da hipótese nula ao nível de 5\% de significância.

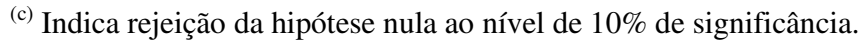


Nas estimações, a variável dependente é medida pela primeira diferença no $\log$ da taxa de investimento e representa, portanto, a taxa de crescimento da formação bruta de capital fixo do setor privado. Em todas as equações, foi inserida uma variável de controle para períodos de instabilidade política, representada por uma dummy que assume valores unitários para os anos de 1985 (fim do regime militar e início da Nova República, com o governo Sarney), 1990 (Plano Collor e Nova Política Industrial, com propostas de profunda reestruturação produtiva da indústria brasileira) e 2002 (eleição presidencial e incerteza sobre a as propostas do candidato do partido de oposição), períodos marcados por expectativas de mudança na condução da política brasileira, que podem ter afetado a credibilidade dos agentes em relação às políticas e gerado incerteza sobre os incentivos. A segunda defasagem da variável dependente foi incluída como um regressor adicional nas equações 1 e 3 (EQ1 e EQ3) para solucionar o problema de autocorrelação nos resíduos. Os resultados das estimações são apresentados na Tabela 2, a seguir. ${ }^{11}$

$\mathrm{Na}$ primeira equação (EQ1), que reflete os modelos do acelerador e neoclássico, observa-se que as variáveis quantitativas, produto e utilização de capacidade foram relevantes na explicação do investimento privado, apontando a demanda agregada como uma importante variável explicativa. Os sinais encontrados para os coeficientes estimados foram positivos, estatisticamente significativos e estão de acordo com a teoria econômica, indicando que aumentos na renda e na atividade econômica estimulam e elevam mais que proporcionalmente o investimento privado no país. Esse resultado é compatível com a maioria dos trabalhos empíricos existentes sobre os determinantes do investimento no Brasil e em outros países em desenvolvimento, onde as variáveis utilizadas para refletir as condições da demanda também foram significativas e relevantes nos modelos estimados. Na primeira equação observa-se também a importância da irreversibilidade do investimento, refletida no coeficiente da primeira defasagem do investimento privado, que foi positivo e significativo, indicando que o investimento corrente é dependente dos seus valores passados. Essa evidência indica a existência de defasagens no processo de tomada de decisão e implementação do investimento privado e sugere que o investimento corrente, além de refletir ajustes parciais do estoque de capital atual a seu nível desejado, tende a acontecer de forma acumulada ou aglomerada no tempo (lumpness). ${ }^{12}$

(11) A equação relacionada à teoria $q$ de Tobin foi omitida da análise em virtude da baixa participação relativa das firmas brasileiras no mercado de capitais - ver CNI (2003) e Desafios (2006). Além disso, a ausência de dados para o período em análise também motivou essa decisão.

(12) Analisando o investimento em máquinas e equipamentos para a indústria manufatureira americana, Doms e Dunne (1993) notam que um pico de investimento é seguido de outro no período seguinte em mais de $40 \%$ das unidades analisadas, indicando aglomeração do investimento no tempo. 
Tabela 2

Determinantes do investimento privado

\begin{tabular}{|c|c|c|c|c|c|c|c|}
\hline \multicolumn{8}{|c|}{ Mínimos Quadrados Ordinários - Variável Dependente: Investimento Privado 1970-2005 } \\
\hline Variáveis & & & & & & & \\
\hline$\underset{\text { (1) (2) }}{\text { Explicativas }}$ & EQ1 & EQ2 & EQ3 & EQ3 ${ }^{\text {Gobetti }}$ & EQ4 & EQ5 & EQ6 \\
\hline \multirow{3}{*}{$\mathrm{C}$} & -0.02058 & -0.01784 & -0.10569 & -0.09105 & -0.02301 & -0.02414 & 0.03564 \\
\hline & {$[-2.80547]^{*}$} & {$[-2.50093]^{*}$} & {$[-0.28708]$} & {$[-0.24899]$} & {$[-3.370051]^{*}$} & {$[-2.915957]^{*}$} & [1.347053] \\
\hline & $(0.00939)$ & $(0.0190)$ & $(0.77642)$ & $(0.8054)$ & $(0.00230)$ & $(0.00710)$ & $(0.18920)$ \\
\hline \multirow{3}{*}{ Dln IP(-1) } & 0.23469 & 0.21208 & 0.22755 & 0.22865 & 0.26837 & 0.27903 & 0.20849 \\
\hline & {$[5.36759]^{*}$} & {$[3.76613]^{*}$} & {$[6.03888]^{*}$} & {$[6.02383]^{*}$} & {$[5.203548]^{*}$} & {$[4.933492]^{*}$} & {$[3.748346]^{*}$} \\
\hline & $(0.00001)$ & $(0.0009)$ & $(0.00000)$ & $(0.0000)$ & $(0.00000)$ & $(0.00000)$ & $(0.00090)$ \\
\hline \multirow{3}{*}{$\mathrm{DlnY}$} & 1.01689 & 0.95990 & 1.00978 & 1.01151 & 1.23335 & 1.24709 & 1.31229 \\
\hline & {$[4.38873]^{*}$} & {$[3.77417]^{*}$} & {$[4.25560]^{*}$} & {$[2.88944]^{*}$} & [8.048686]* & {$[6.647783]^{*}$} & {$[7.171562]^{*}$} \\
\hline & $(0.00017)$ & $(0.0008)$ & $(0.00026)$ & $(0.0002)$ & $(0.00000)$ & $(0.00000)$ & $(0.00000)$ \\
\hline \multirow{3}{*}{ Dln UTCAP } & 1.37616 & 1.24881 & 1.37941 & 1.37853 & 1.07225 & 1.08612 & 1.10767 \\
\hline & {$[6.19214]^{*}$} & {$[6.84637]^{*}$} & {$[6.05652]^{*}$} & {$[6.05329]^{*}$} & [6.972757]* & {$[5.430009]^{*}$} & {$[6.675121]^{*}$} \\
\hline & $(0.0000)$ & $(0.0000)$ & $(0.0000)$ & $(0.0000)$ & $(0.0000)$ & $(0.0000)$ & $(0.0000)$ \\
\hline \multirow{3}{*}{$\mathrm{R}(-1)$} & 0.00023 & 0.00049 & 0.00019 & 0.00019 & 0.00035 & 0.00038 & 0.00003 \\
\hline & [1.04882] & [1.83542] & {$[0.79538]$} & [0.831013] & [1.140392] & [1.357576] & [0.083639] \\
\hline & $(0.30391)$ & $(0.0779)$ & $(0.43388)$ & $(0.4138)$ & $(0.26410)$ & $(0.18580)$ & $(0.93400)$ \\
\hline \multirow{3}{*}{ Dln CRED(-2) } & & 0.12024 & & & & & \\
\hline & & {$[2.29087]^{* *}$} & & & & & \\
\hline & & $(0.0303)$ & & & & & \\
\hline \multirow{3}{*}{$\ln I G$} & & & 0.00812 & 0.00672 & & & \\
\hline & & & {$[0.23255]$} & [0.193869] & & & \\
\hline & & & $(0.81800)$ & $(0.8478)$ & & & \\
\hline \multirow{3}{*}{ Dln INST } & & & & & -0.01406 & & \\
\hline & & & & & {$[-2.629167]^{*}$} & & \\
\hline & & & & & $(0.01400)$ & & \\
\hline \multirow{3}{*}{ D EE } & & & & & & -0.00386 & \\
\hline & & & & & & [-1.312162] & \\
\hline & & & & & & $(0.20050)$ & \\
\hline \multirow{3}{*}{$\ln \mathrm{E}$} & & & & & & & -0.05483 \\
\hline & & & & & & & {$[-2.19204]^{*}$} \\
\hline & & & & & & & $(0.03720)$ \\
\hline \multirow{3}{*}{ Dln IP(-2) } & 0.14679 & & 0.14666 & 0.14662 & & & \\
\hline & {$[2.96608]^{*}$} & & {$[2.88328]^{*}$} & {$[2.88944]^{*}$} & & & \\
\hline & $(0.00639)$ & & $(0.00798)$ & $(0.0079)$ & & & \\
\hline \multirow{3}{*}{$\begin{array}{l}\text { Instabilidade } \\
\text { Política }\end{array}$} & -0.02998 & -0.03827 & -0.03041 & -0.030349 & -0.04599 & -0.05065 & -0.03504 \\
\hline & {$[-2.79705]^{*}$} & {$[-3.72494]^{*}$} & {$[-2.78481]^{*}$} & {$[-2.77438]^{*}$} & {$[-3.83004]^{*}$} & {$[-4.279792]^{*}$} & {$[-3.599227]^{*}$} \\
\hline & $(0.00958)$ & $(0.0010)$ & $(0.01006)$ & $(0.0103)$ & $(0.00070)$ & $(0.00020)$ & $(0.00130)$ \\
\hline $\mathrm{R}^{2}$ & 0.92092 & 0.92006 & 0.92109 & 0.92103 & 0.92499 & 0.91442 & 0.92067 \\
\hline $\mathrm{R}^{2}$ Ajustado & 0.90267 & 0.90161 & 0.89900 & 0.89893 & 0.90832 & 0.89540 & 0.90304 \\
\hline Estatística F & 50.46197 & 49.87174 & 41.68805 & 41.65766 & 55.49332 & 48.08299 & 52.22263 \\
\hline $\operatorname{Prob}(\mathrm{F})$ & 0.00000 & 0.00000 & 0.00000 & 0.00000 & 0.00000 & 0.00000 & 0.00000 \\
\hline Teste $\mathrm{LM}^{(3)}$ & 0.17582 & 0.13894 & 0.17331 & 0.17230 & 0.12733 & 0.14035 & 0.01676 \\
\hline Hausman-Wu ${ }^{(4)}$ & 0.38991 & 0.89120 & 0.40605 & 0.40440 & 0.23480 & 0.44195 & 0.78440 \\
\hline $\begin{array}{l}\text { Estatística t em c } \\
\text { rênteses; }{ }^{(2)}(*) \text { e } \\
\text { orrelação Serial. }\end{array}$ & alores para & $\begin{array}{l}\text { da para het } \\
\text { gnificância } \\
\text { hipótese } n\end{array}$ & $\begin{array}{l}\text { oscedasticic } \\
5 \% \text { e } 10 \% \\
\text { la de ausên }\end{array}$ & $\begin{array}{l}\text { dade e autoco } \\
\text { respectivam } \\
\text { cia de autocc }\end{array}$ & $\begin{array}{l}\text { rrelação por I } \\
\text { hente; }{ }^{(3)} \text { Teste } \\
\text { orrelação; }{ }^{(4)} \mathrm{T}\end{array}$ & $\begin{array}{l}\text { Newey-West, } \\
\text { de Breusch-C } \\
\text { Teste de endo }\end{array}$ & $\begin{array}{l}\text { p-valores em } \\
\text { Godfrey para } \\
\text { geneidade de }\end{array}$ \\
\hline
\end{tabular}


A taxa de juros real apresentou coeficiente positivo e não significativo em todas as equações estimadas. Apesar do sinal dos coeficientes estimados irem de encontro ao esperado teoricamente, os coeficientes são numericamente muito próximos de zero (e não significativos), indicando que esta proxy do custo de utilização do capital não contribuiu para reduções no investimento privado. Essa evidência também foi encontrada por Reis et al. (1999), que também estimam equações a partir de dados macroeconômicos para o período 1972-1996. Apesar da importância teórica do custo do capital na determinação do investimento, a dificuldade de se obter coeficientes significativos e com sinal negativo para essa variável é muito disseminada na literatura. Para o caso brasileiro, em particular, coeficientes tão próximos de zero para o custo de capital podem ser explicados, por um lado, pela tradição das empresas de não buscarem financiamento externo à firma ${ }^{13}$ e, por outro, pela volatilidade das taxas de juros durante o período de alta inflação, fazendo com que a taxa de juros deixasse de ser referência para o cálculo do custo de oportunidade do investimento.

As incertezas provocadas por choques políticos (capturados pela variável dummy "Instabilidade Política") também foram relevantes na determinação do investimento no Brasil, e o coeficiente negativo encontrado indica que em períodos de incerteza política o investimento privado é menor. Este resultado denota que a credibilidade dos agentes privados acerca da estabilidade da estrutura de incentivos e da condução de reformas políticas foi determinante para a realização do investimento privado no Brasil. Assim, a implementação de políticas responsáveis e consistentes ao longo do tempo é essencial para minimizar as incertezas políticas e incentivar o investimento privado no país.

A importância da disponibilidade de crédito sobre o investimento privado no Brasil é investigada na Equação 2 (EQ2). Os resultados indicam que um aumento na oferta de crédito, por meio de uma elevação das operações de crédito direcionadas ao setor privado, eleva o investimento privado nos períodos seguintes, confirmando a hipótese de que as empresas brasileiras enfrentam restrições de crédito. O resultado obtido é compatível com os estudos de Sundararajan e Takur (1980), Blejer e Khan (1984), Garcia (1987), Left e Sato (1988), Studart (1992), Jacinto e Ribeiro (1998) e Ribeiro e Teixeira (2001), que incluem variáveis financeiras nos estudos empíricos e indicam que a disponibilidade de crédito é uma das variáveis relevantes para o investimento privado nos países em desenvolvimento. Terra (2003) investigou especificamente a restrição de crédito sobre as decisões de investimento das empresas brasileiras e confirmou que as firmas brasileiras operam sob restrições financeiras em suas decisões de investimento. Dessa maneira, políticas públicas que aumentem a oferta

(13) Terra (2003) mostra que o fluxo de vendas determina o investimento, indicando autofinanciamento e/ou restrição financeira. 
de crédito disponível para o investimento privado, assim como o fortalecimento institucional do mercado de capitais no país, podem contribuir para que as firmas tenham acesso a um volume maior de recursos para financiar seu crescimento de longo prazo.

A influência do investimento público sobre o investimento do setor privado no Brasil é verificada pela Equação 3 (EQ3). O coeficiente da variável investimento público apresentou sinal positivo, o que sugeriria a dominância do efeito de complementaridade. No entanto, o coeficiente apresentou-se não significativo. Em Cruz e Teixeira (1999), os coeficientes do vetor de cointegração também indicam que os investimentos público e privado são complementares. ${ }^{14} \mathrm{O}$ resultado não significativo obtido na EQ3 pode ser explicado pela diminuição da capacidade do governo brasileiro de realizar investimentos em infraestrutura no período analisado. A equação 3 foi também estimada utilizando-se os dados para o investimento público apresentados por Gobetti (2009). Apesar de relevantes do ponto de vista metodológico, os problemas de mensuração apontados por Gobetti (2006) não afetaram fortemente os coeficientes estimados. Como esperado, o coeficiente da variável investimento público sofre uma pequena redução, mas continua positivo e não-significativo estatisticamente (ver EQ3 ${ }^{\text {Gobetti }}$ ).

A Equação 4 (EQ4) analisa o efeito da instabilidade econômica sobre o investimento privado no Brasil. Observa-se que o coeficiente da variável de instabilidade apresentou sinal negativo, sugerindo que períodos de alta instabilidade econômica (alta variabilidade da inflação, juros e câmbio) podem influenciar negativamente o investimento privado.

Em relação às condições externas, a Equação 5 (EQ5) sugere que os serviços da dívida externa não afetaram o investimento privado de maneira significativa durante o período analisado. Uma possível explicação para esse resultado consiste na participação do setor público na captação de recursos em períodos de crises externas, atuando como avalista dos empréstimos contraídos pelo setor privado e financiando os investimentos nos períodos de restrição externa ou mesmo a melhoria das condições de financiamento externo observadas a partir da década de 1990.

Por fim, o coeficiente estimado para a taxa de câmbio foi significativo e apresentou sinal negativo (Equação 6 - EQ6), indicando que uma taxa de câmbio mais elevada (ou mais desvalorizada) desestimula a importação de bens de capital, o que, por conseguinte, reduz o investimento da economia. Esse resultado é confirmado por Ribeiro e Teixeira (2001), cujos resultados indicam que a primeira

(14) Os resultados apresentados de Studart (1992), Rocha e Teixeira (1996), Jacinto e Ribeiro (1998) e Cruz e Teixeira (1999) apontam para uma relação de "crowding-out" entre os investimentos público e privado no curto prazo, sugerindo a existência de uma competição por recursos físicos na economia brasileira. 
diferença da taxa de câmbio possui efeito significante e negativo sobre o investimento privado no Brasil. Convém ressaltar, no entanto, que os resíduos desta equação apresentam autocorrelação que, associada à presença da variável dependente defasada dentre os regressores, torna o estimador MQO inconsistente. ${ }^{15}$

Verifica-se ainda na Tabela 2 que as equações estimadas estão bem ajustadas com coeficientes de determinação ajustado na ordem de $90 \%$ e que os resíduos não apresentam autocorrelação estatisticamente significativa (com exceção da EQ6). Dada a preocupação de que o produto (expresso pela variável $D \ln Y)$ possa ser endogenamente determinado com a taxa de investimento $(D \ln I P)$ tornando o estimador de MQO inconsistente mesmo na ausência de autocorrelação, implementou-se o teste de Hausman modificado. O teste consiste em verificar a significância estatística dos resíduos estimados obtidos a partir de uma regressão auxiliar, onde a variável suspeita de endogeneidade (no caso, $D \ln Y$ ) é regredida contra os regressores presentes na equação principal e alguns possíveis instrumentos (utilizamos valores defasados do produto e do nível de utilização da capacidade). Então a regressão principal é aumentada pela inclusão dos resíduos estimados da regressão auxiliar e o coeficiente dos resíduos é analisado para significância estatística. Os autores mostram que se os estimadores MQO são consistentes, os resíduos dessa regressão auxiliar não serão significativos. A Tabela 2 apresenta os p-valores obtidos nos testes de significância dos resíduos para cada equação estimada. Verifica-se que podemos considerar os estimadores utilizados consistentes.

No que tange à robustez dos resultados obtidos, é importante notar que os coeficientes estimados para as variáveis presentes em todas as equações não se mostraram sensíveis a mudanças nas especificações. Os principais resultados quantitativos e qualitativos não se alteram de forma relevante para as variáveis presentes nas Equações de 1 a 6.

Analisando-se comparativamente os modelos, observa-se que as Equações 1,4 e 6 são as que apresentam graus de ajustamento mais elevados, sugerindo que estes modelos foram os que melhor refletiram o investimento no Brasil no período considerado. Em relação ao poder preditivo das equações estimadas, a Tabela 3 apresenta os valores observados para o investimento privado e taxa de investimento do setor privado no ano de 2005, e os valores previstos pelos modelos para o mesmo ano.

(15) Infelizmente, a inclusão de defasagens não foi capaz de eliminar o problema da autocorrelação. Possivelmente, há problemas de especificação nesta equação e os resultados devem ser interpretados com cautela. 
Tabela 3

Estimativas do investimento e taxa de investimento do setor privado Ano de 2005 (R\$ Milhões)

\begin{tabular}{c|r|r|r|r|r|r|r}
\hline & $\begin{array}{c}\text { Valor } \\
\text { Verdadeiro }\end{array}$ & \multicolumn{7}{|c}{ Valores Previstos } \\
\hline & & \multicolumn{1}{|c|}{ EQ1 } & \multicolumn{1}{|c|}{ EQ2 } & EQ3 & EQ4 & EQ5 & EQ6 \\
\hline IP & 315010.99 & 316334.41313140 .37316527 .54316350 .71315095 .23 & 320344.94 \\
\hline IP/PIB (\%) & 14.67 & 14.83 & 14.61 & 14.81 & 14.58 & 15.04 & 15.01 \\
\hline Erro Absoluto & & 0.011 & 0.004 & 0.010 & 0.006 & 0.025 & 0.023 \\
\hline
\end{tabular}

Fonte: Elaboração própria com base nas equações estimadas.

A análise da diferença entre o valor observado e o valor previsto por cada equação indica que os modelos que forneceriam a melhor previsão para o investimento do setor privado no ano de 2005 seriam as equações 2, 3 e 4 - as que apresentaram menor percentual de erro médio absoluto (MAPE). Por esse critério, pode-se inferir que, além das condições de demanda, a disponibilidade de crédito e a instabilidade econômica e política representaram variáveis importantes para o investimento privado no Brasil do período analisado.

\section{Comentários finais}

$\mathrm{O}$ presente artigo analisou os principais determinantes do investimento privado no Brasil para o período 1970 a 2005, valendo-se dos dados do Novo Sistema de Contas Nacionais do IBGE recentemente divulgados pelo Ipea. As evidências empíricas obtidas nos modelos testados confirmam a predominância das variáveis quantitativas, como produto e utilização de capacidade, indicando que aumentos na renda e na atividade econômica estimularam o investimento privado no Brasil durante o período estudado. O efeito acelerador verificado é complementado pela existência de defasagens no processo de decisão e implementação do investimento privado, sugerindo a hipótese de irreversibilidade do investimento. $\mathrm{O}$ investimento público apresentou relação positiva com o investimento privado, porém não significativa. Apesar disso, estudos mostram a importância da complementaridade entre os investimentos público e privados para o crescimento econômico, principalmente no que tange a investimentos em infraestrutura e treinamento.

O custo de utilização do capital, mensurado pela taxa de juros real, não se mostrou significativo, indicando que a taxa de juros real não contribuiu para reduções do investimento privado, resultado compatível com o alto volume de autofinanciamento das empresas brasileiras. $\mathrm{O}$ volume de crédito ao setor privado, no sentido amplo, por outro lado, mostrou-se importante afetando positivamente o investimento privado. Neste aspecto, a ampliação de linhas de financiamento de longo prazo, adequadas à formação de capital fixo pelas empresas, seria de 
extrema relevância para aumentar a taxa de investimento da economia. Segundo a CNI (2003), o financiamento à atividade produtiva no Brasil é escasso e constitui um obstáculo ao crescimento das empresas e do país. As taxas de juros reais nos empréstimos bancários são elevadas, o montante de crédito expresso como proporção do Produto Interno Bruto (PIB) é mais baixo que nos países industrializados e nas economias emergentes. $\mathrm{O}$ valor do crédito bancário no Brasil, em 2004, era equivalente a 25,2\% do PIB e encontra-se hoje em torno de $35 \%$ do PIB, enquanto que nos países desenvolvidos, como Japão, este equivalia a 94,4\% do PIB, e a 104\% do PIB nos países da área do Euro. Em outras economias em desenvolvimento, a proporção do crédito bancário em relação ao PIB também é maior, como no Chile (57\%), e na África do Sul (73\%). O Brasil só está acima de poucos mercados emergentes, como México (14,3\%) e Argentina (10,4\%). Uma alternativa de financiamento seria o mercado de capitais. No entanto, o mercado de capitais ainda é pouco desenvolvido no país (o valor total das ações negociadas na Bolsa de Valores de São Paulo foi de 104 bilhões de dólares em 2004, perdendo para a Turquia, com 147 bilhões de dólares, e para a China, com 517 bilhões de dólares). $\mathrm{O}$ valor total de todos os tipos de títulos que as empresas brasileiras usam para captar recursos foi de apenas $0,6 \%$ do PIB do país, inferior aos 11,3\% do Chile ou 38,2\% na Malásia. O financiamento externo, por sua vez, é instável, além de ter se tornado mais arriscado com a introdução do regime de câmbio flutuante (ver Desafios, 2006).

Além do crédito, a instabilidade política e econômica e as desvalorizações cambiais exerceram, em média, efeitos adversos sobre a formação bruta de capital fixo do setor privado na economia brasileira no período estudado. Esses resultados indicam a existência de restrições de crédito para firmas brasileiras e apontam para a importância da estabilidade macroeconômica e da condução de políticas públicas para a realização do investimento privado. Portanto, para que o investimento aumente é preciso que o governo implemente políticas econômicas responsáveis e consistentes ao longo do tempo, de forma a minimizar as incertezas econômicas e políticas, e dê condições para a ampliação do volume de crédito de longo prazo disponível para o investimento privado no país.

\section{Referências bibliográficas}

BANCO CENTRAL DO BRASIL. Economia e Finanças. Séries Temporais. 2007. Disponível em: http://www4.bcb.gov.br/?SERIESTEMP.

Relatório de inflação. Indústria: capacidade produtiva e investimentos. set. 2004. p. 21-27. Disponível em: http://www.bcb.gov.br/?RELINF.

BERNANKE, B. S. Irreversibility, uncertainty and cyclical investment. Quarterly Journal of Economics. v. 98, p. 85-106, Feb. 1983. 
BLEJER, M.; KHAN, M. Government policy and private investment in developing countries. IMF Staff Papers, n. 31 (2), p. 379-403, Jun. 1984.

BOUCEKKINE, R.; CRUZ, B. Technological progress and investment: microeconomic foundations and macroeconomic implications. Brasília: Ipea, 2006. (Texto para Discussão, n. 1170).

CABALlERO, R. J. Aggregate investment. In: TAYLOR, J. B.; WOODFORD, M. Handbook of macroeconomics. Elsevier Science, 1999. v. 1.

On the dynamics of aggregate investment. In: SERVÉN, L.; SOLIMANO, A. (Ed.). Striving for growth after adjustment. Washington, DC: The World Bank, 1993.

CÂNDIDO JÚNIOR, J. O. Efeitos do investimento público sobre o produto e a produtividade: uma análise empírica. Brasília: Ipea, 2006. 41p. (Texto para Discussão, n. 1024).

CARDOSO, E. O investimento privado na América Latina. Revista de Economia Política, v. 12, n. 4 (48), out./dez. 1992.

CHIRINKO, R. S. Business fixed investment spending: modeling strategies, empirical results, and policy implications. Journal of Economic Literature, v. 31, p. 1875-1911, Dec. 1993.

CLARK, J. M. Business acceleration and the law of demand: a technical factor in economic cycles. Journal of Political Economy, 25, p. 217-235, Mar. 1917.

Additional note on business acceleration and the law of demand. In: AMERICAN Economic Association, Readings in Business Cycle Theory. 1944.

CONFEDERAÇÃO NACIONAL DA INDÚSTRIA. Financiamento no Brasil: desafio ao crescimento. Brasília: Unidade de Política Econômica (PEC), 2003. 56p.

CRUZ, B. O.; TEIXEIRA, J. R. The impact of public investment on private investment in Brazil, 1947-1990. Cepal Review. v. 67, p.75-84, abr. 1999.

DAILAMI, M. Expectations, stock market volatility, and private investment behavior: theory and empirical evidence for Brazil. Washington, D.C.: World Bank, Country Economics Department, 1987.

DESAFIOS. Revista Desafios do Desenvolvimento. Instituto de Pesquisa Econômica Aplicada. Edição 19, Ano 3, fev, Reportagem Mercado Engessado (Ottoni Fernandes Jr.). São Paulo. 2006.

DICKEY, D.; FULLER, W. A. Likelihood ratio statistics for autoregressive time series with a unit root. Econometrica, v. 49, n. 4, p. 1057-1072, jul. 1981.

ELLIOTT, G.; ROTHENBERG, T. J.; STOCK, J. H. Efficient tests for an autoregressive unit root. Econometrica, v. 64, p. 813-836, 1996.

FUNDAÇÃO GETÚlIO VARGAS. Divisão de Gestão de Dados (DGD). 2007. Disponível em: http://www2.fgv.br/dgd/asp/dsp_FGVDADOS.asp.

FAZZARI, S.; HUBBART, R.; PETERSEN, B. Financing constraints and corporate investment. Brookings Papers on Economic Activity, 1, p. 141-195, 1988. 
Viviane Luporini / Joana Alves

GALBIS, V. Money, investment and growth in Latin America, 1961-1973. Economic Development and Cultural Change. v. 27, n. 3, p. 423-443, Mar. 1979.

GARCIA, E. Neo-keynesian models in planning and macroeconomic policies: the experience of ILPES. Economic Commission for Latin America and the Caribbean (ECLAC). Santiago do Chile, 1987.

GOBETTI, S. W. Estimativa dos investimentos públicos: um novo modelo de análise da execução orçamentária aplicado às Contas Nacionais. Monografia, XI Prêmio Tesouro Nacional, 2006. Mimeografado.

Qual a real taxa de investimento público no Brasil? Brasília, DF: [s.n, s.d.].

GRENNE, J.; VILLANUEVA, D. Private investment in developing countries: an empirical analysis. IMF Staff Papers. v. 38, n. 1, 1991. (2009).

HARROD, R. F. An essay on dynamic theory. Economic Journal, 49, p. 14-33, Jun. 1939.

HICKS, J. R. A contribution to the theory of the trade cycle. Oxford: Oxford University Press, 1950.

INSTITUTO BRASILEIRO DE GEOGRAFIA E ESTATÍSTICA (IBGE). Sistema de Contas Nacionais Consolidadas. 2007. Disponível em http://www.ibge.gov.br/home/estatistica/economia/contasnacionais/referencia2000/2005/ default.shtm.

JACINTO, P.; RIBEIRO, E. Cointegração, efeitos crowding-in e crowding-out entre investimento público e privado no Brasil: 1973-1989. Teoria e Evidência Econômica, Passo Fundo, v. 6, n. 11, p. 143-156, nov. 1998.

JORGENSON, D. W. Capital theory and investment behavior. American Economic Review, v. 53, n. 2, p.247-259, May 1963.

KEYNES, J. M. The general theory of employment, interest, and money. New York: A Harvest BHJ Book. 1936.

KWIATKOWSKI, D.; PHILLIPS, P. C. B.; SCHMIDT, P.; SHIN, Y. Testing the null hypothesis of stationary against the alternative of a unit root. Journal of Econometrics, v. 54, p. 159-178, 1992.

LEFF, N.; SATO, K. Estimating investment and savings functions for developing countries, with an application to Latin America. International Economic Journal, v. 2, n. 3, p. 1-17, 1988.

LOVE, J. Export instability, imports and investment in developing countries. Journal of Development Studies, v. 25, n. 2, p. 183-191, Jan. 1989.

MADDALA, G. G. Introduction to econometric. 3rd. ed. New York: McGraw - Hill, 1992.

MELO, G. M.; RODRIGUES JR, W. Determinantes do investimento privado no Brasil: 1970-1995. Brasília: Ipea, 1998. 35p. (Texto para Discussão, n. 605). 
MORANDI, L.; REIS, E. J. Estoque de capital fixo no Brasil - 1950-2002. In: ENCONTRO NACIONAL DE ECONOMIA, 32, João Pessoa, PB. João Pessoa: Anpec 07-10 de dezembro, 2004.

MUINHOS, M. K.; ALVES, S. A. L. Medium size macroeconomic model for the Brazilian economy. Brasília: Banco Central do Brasil, 2003. (Working Paper Series, n. 64).

PERRON, P. The great crash, the oil price shock, and the unit root hypothesis. Econometrica, v. 57, n. 6, 1989.

RAMA, M. Empirical investment equations for developing countries. In: SERVÉN, L.; SOLIMANO, A. (Ed.). Striving for growth after adjustment. Washington, DC: The World Bank, 1993.

REIS, E.; CAVALCANTI, M. A.; CASTRO, A. R.; ROSSI JR, J. L.; EMERSON, R. A.; HERNANDES, B. M. Model for projections and simulations of the Brazilian economy. Brasília: Ipea, 1999. (Texto para Discussão, n. 619).

RIBEIRO, M. B.; TEIXEIRA, J. R. An econometric analysis of private-sector investment in Brazil. Cepal Review, n. 74, p. 153-166, Aug. 2001.

ROCHA, C.; TEIXEIRA, J. Complementariedade versus substituição entre investimento público e privado na economia brasileira: 1965-90. Revista Brasileira de Economia, v. 50, n. 3, p. 378-384, jul./set. 1996.

RONCI, M. V. Uma nota sobre a especificação da função de investimento agregado para países em desenvolvimento. Revista Brasileira de Economia, Rio de Janeiro, v. 42, n. 2, p. 179-194, abr./jun. 1988.

Janeiro: FGV, 1991.

Política econômica e investimento privado no Brasil (1955-82). Rio de

SAMUELSON, P. A. Interaction between the multiplier analysis and principle of acceleration. Review of Economics and Statistics, 21, p. 75-78, 1939.

SANTOS, C. H.; PIRES, M. C. C. Qual a sensibilidade dos investimentos privados a aumentos na carga tributária brasileira? Uma investigação econométrica. Brasília: Coordenação de Finanças Públicas (DIRUR/IPEA), 2007.

SERVÉN, L; SOLIMANO, A. Striving for growth after adjustment: the role of capital formation. Washington, DC: The World Bank, 1993.

Private investment and macroeconomic adjustment: a survey. In: SERVÉN, L.; SOLIMANO, A. (Ed.). Striving for growth after adjustment. Washington, DC: The World Bank, 1993a.

STIGLITZ, J. E.; WEISS, A. Credit rationing in markets with imperfect information. American Economic Review, v. 71, n. 3, p. 393-410, 1981.

STUDART, G. Investimento público e formação de capital do setor privado no Brasil: análise empírica da relação de curto e de longo prazos durante o período 1972-1989. Dissertação (Mestrado)-PUC, Rio de Janeiro, 1992.

SUNDARARAJAN, V.; THAKUR, S. Public investment, crowding out and growth: a.dynamic model applied to India and Korea. IMF Staff Papers, v. 27, n. 4, 1980. 
Viviane Luporini / Joana Alves

TERRA, C. M. Credit constraints in Brazilian firms: evidence from panel data. Revista Brasileira de Economia, v. 57, n. 2, p. 443-464, abr./jun. 2003.

TOBIN, J. Guiana. Journal of Money, Credit, and Banking, v. 1, n. 1, p. 15-29, 1969.

VOGEL, R.; BUSER, S. Inflation, financial repression and capital formation in Latin America. In: McKINNON, R. Money and finance in economic development: essays in honor of Edward S. Shaw. New York: Marcel Dekker, 1976. 


\section{Apêndice}

\section{Variáveis utilizadas}

\begin{tabular}{|c|c|c|c|c|c|c|c|c|c|}
\hline Período & $\begin{array}{l}\text { Log } \\
\text { (IP) }\end{array}$ & $\begin{array}{l}\text { Log } \\
\text { (Y) }\end{array}$ & $\begin{array}{c}\text { Log } \\
\text { (UTCAP) }\end{array}$ & $\begin{array}{c}\text { Log } \\
\text { (CRED) }\end{array}$ & R (\%) & $\begin{array}{l}\text { Log } \\
\text { (IG) }\end{array}$ & $\begin{array}{c}\text { Log } \\
\text { (INST) }\end{array}$ & $\begin{array}{l}\text { EE } \\
(\%)\end{array}$ & $\begin{array}{l}\text { Log } \\
\text { (E) }\end{array}$ \\
\hline 1970 & 11.5518 & 13.2152 & 4.4505 & 12.1264 & 5.897 & 10.369 & n.a. & 2.40 & 1.1080 \\
\hline 1971 & 1.7196 & 13.3226 & 4.4601 & 12.3450 & 4.736 & 10.425 & 0.4336 & 2.90 & 1.1054 \\
\hline 1972 & 1.9045 & 3.4354 & 4.4688 & 12.6121 & 5.338 & 10.462 & 0.3418 & 3.00 & 1.0935 \\
\hline 1973 & 2.1060 & 13.5662 & 4.4970 & 12.9206 & 5.129 & 10.603 & 0.2037 & 3.00 & 1.0467 \\
\hline 1974 & 2.2374 & 13.6446 & 4.4858 & 13.1065 & -5.379 & 10.693 & 1.2529 & 3.10 & 0.9994 \\
\hline 1975 & 2.3391 & 13.6949 & 4.4659 & 13.3036 & 1.582 & 10.750 & 1.0252 & 3.30 & 1.0233 \\
\hline 1976 & 2.3941 & 13.7926 & 4.4830 & 13.4250 & -7.246 & 10.879 & 1.9956 & 3.70 & 1.0064 \\
\hline 1977 & .4128 & 13.8407 & 4.4427 & 13.4968 & 3.931 & 10.713 & 1.1805 & 4.40 & 0.9956 \\
\hline 1978 & 2.4745 & 13.8893 & 4.4278 & 13.5806 & 3.742 & 10.671 & 0.5504 & 5.30 & 0.9868 \\
\hline 1979 & & 13.9547 & & 13.6013 & & & & 6.00 & 1.0619 \\
\hline 1980 & .6867 & 14.0427 & 4.4338 & 13.4769 & -25.605 & 10.487 & 1.3344 & 7.00 & 1.1655 \\
\hline 1981 & 2.5463 & 13.9992 & 4.3503 & 13.2166 & -0.646 & 10.448 & 1.3060 & 7.60 & 1.0913 \\
\hline & & 14.0075 & & & & & & 7.00 & 1.1373 \\
\hline 1983 & & 3.9778 & & & & & & 7.80 & 1.4025 \\
\hline 1984 & 2.2931 & 14.0304 & 4.3041 & 13.0756 & 11.292 & 10.219 & 1.9513 & 7.10 & 1.4435 \\
\hline & & 14.1059 & & & & & & 5.80 & 1.5087 \\
\hline 1986 & & 14.1782 & & 13.1701 & & & & 5.20 & 1.4317 \\
\hline 1987 & 2.5298 & 14.2129 & 4.3914 & 13.2648 & 1.577 & 10.749 & 2.0485 & 7.30 & 1.3460 \\
\hline & & & & & & & & 4.70 & \\
\hline & & 14.2434 & & & & & & 4.40 & 0.9990 \\
\hline & & & & & & & & 4.40 & 0.8874 \\
\hline 1991 & & 14.2092 & & & & & & 4.40 & 1.0743 \\
\hline 1992 & 2.2060 & 14.2045 & 4.2767 & 12.8759 & 36.481 & 10.743 & 3.1515 & 4.20 & 1.1209 \\
\hline 1993 & & 14.2501 & 4.3406 & 12.9963 & 8.048 & 10.684 & & 3.10 & 1.0329 \\
\hline 1994 & & 14.3020 & & & 4.752 & & & 2.70 & 0.8266 \\
\hline & & & & & & & & 3.10 & 0.7001 \\
\hline 1996 & 12.5665 & 14.3665 & 4.4037 & 13.1958 & & 10.575 & & 4.40 & 0.7148 \\
\hline 1997 & & 14.3997 & & & 15.545 & 10.468 & & 5.30 & 0.7318 \\
\hline 1998 & & & & & & & & 10.40 & 0.7829 \\
\hline 1999 & 12.5928 & 14.4026 & 4.3883 & 13.2203 & 4.414 & 10.300 & 0.9514 & 7.60 & 1.1443 \\
\hline 2000 & 12.6243 & 14.4448 & 4.4167 & 13.1763 & 6.599 & 10.508 & 0.4710 & 8.90 & 1.0570 \\
\hline 2001 & & 14.4578 & & & 6.493 & & & 9.90 & 1.2365 \\
\hline 2002 & 12.5541 & 14.4841 & 4.3748 & 13.1424 & -6.807 & 10.617 & 1.2685 & 9.60 & 1.3429 \\
\hline 2003 & 12.5378 & 14.4955 & 4.3879 & 13.0199 & 10.794 & 10.325 & 1.3127 & 7.80 & 1.2124 \\
\hline 2004 & 12.6251 & 14.5510 & 4.4227 & 13.0860 & 1.549 & 10.412 & 0.7067 & 7.50 & 1.0982 \\
\hline 2005 & 12.6604 & 14.5800 & 4.4365 & 13.2175 & 14.723 & 10.449 & 2.2703 & 5.30 & 0.8900 \\
\hline
\end{tabular}


Tabela A.1

Estudos empíricos sobre investimento

\begin{tabular}{|c|c|c|c|c|c|c|c|c|c|c|}
\hline & Países & Dados & $\begin{array}{l}\text { Variável } \\
\text { Endógena }\end{array}$ & $\begin{array}{l}\text { Demanda } \\
\text { Agregada }\end{array}$ & $\begin{array}{l}\text { Preços } \\
\text { Fatores }\end{array}$ & \begin{tabular}{|c|} 
Disponibilidade \\
Crédito
\end{tabular} & $\begin{array}{l}\text { Investimento } \\
\text { Público }\end{array}$ & \begin{tabular}{|c|} 
Instabilidade \\
Econômica
\end{tabular} & \begin{tabular}{|c|} 
Condições \\
Externas
\end{tabular} & Técnica \\
\hline Vogel e Buser (1976) & $(1)$ & $\begin{array}{c}\text { Anual } \\
1950-1972\end{array}$ & $\left(I P_{t}+I G_{t}\right) / Y_{t}$ & $\begin{array}{l}\text { VMC (n.s.) } \\
\text { DP (n.s.) }\end{array}$ & Omitida & Omitida & Omitida & Omitida & Omitida & MQO \\
\hline Galbis (1979) & (2) & $\begin{array}{c}\text { Anual } \\
1961-1973\end{array}$ & $I P_{t} / Y_{t}$ & Omitida & $P_{t} \quad(-)$ & Omitida & $I G_{t} / Y_{t}(+)$ & Omitida & Omitida & MQO \\
\hline $\begin{array}{c}\text { Sundararajan e Takur } \\
(1980)\end{array}$ & (3) & $\begin{array}{c}\text { Anual } \\
1960-1976\end{array}$ & $I P_{t}$ & $\underset{Q P P_{t-1}}{Q(++)} \stackrel{(++)}{(+)}$ & $\begin{array}{c}C_{t-1} / W_{t-1} \\
C_{t-2} / W_{t-2}\end{array}$ & $(S-I G)_{t}(++)$ & $K G_{t}(+)$ & Omitida & Omitida & MQO \\
\hline Blejer e Khan (1984) & (4) & $\begin{array}{c}\text { Anual } \\
1971-1979\end{array}$ & $I P_{t}$ & $Y_{t-1}(++)$ & Omitida & $\Delta F_{t}(++)$ & $I G_{t} \quad(--)$ & $Y_{t}-Y^{T}(--)$ & Omitida & MQO \\
\hline Dailami (1987) & Brasil & 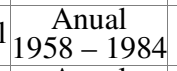 & $\Delta I P_{t}$ & $\Delta Y_{t}(++)$ & $\begin{array}{c}\Delta(C / P)_{t}(-) \\
\Delta(W / P)^{(+)}\end{array}$ & Omitida & Omitida & PR (- -) & Omitida & MV \\
\hline Garcia (1987) & (5) & $\begin{array}{c}\text { Anual } \\
1970-1985\end{array}$ & $I P_{t}$ & $Y_{t}^{*}(++)$ & Omitida & $F_{t-1}(++)$ & Omitida & Omitida & Omitida & MQO \\
\hline Leff e Sato (1988) & (6) & $\begin{array}{c}\text { Anual } \\
1955-1983\end{array}$ & $I P_{t}+I G_{t}$ & $\Delta Y_{t}(++)$ & $P_{t}^{e}(--)$ & $\Delta F_{t}(++)$ & Omitida & Omitida & Omitida & MQO(3) \\
\hline Ronci (1991) & Brasil & 1 Anual 1952 & $I P_{t}$ & $Y_{t}(++)$ & $\begin{array}{c}C_{t} / W_{t} \quad \text { (n.s.) } \\
C_{t-1} / E_{t-1} \quad(++)\end{array}$ & Omitida & $K G_{t}$ (n.s.) & Omitida & Omitida & MQO \\
\hline Love (1989) & (7) & $\begin{array}{c}\text { Anual } \\
1960-1984\end{array}$ & $\Delta\left(I P_{t}+I G_{t}\right)$ & Omitida & Omitida & Omitida & Omitida & Omitida & (+) $\operatorname{RES}$ & MQO \\
\hline $\begin{array}{c}\text { Grenne e Villanueva } \\
(1991)\end{array}$ & (8) & $\begin{array}{c}\text { Anual } \\
1975-1987\end{array}$ & $I P_{t} / Y_{t}$ & $Y_{t-1}^{*}(++)$ & $R_{t}(--)$ & Omitida & $I G_{t} / Y_{t}(++)$ & $\begin{array}{c}D_{t} / Y_{t-1}(--) \\
P_{+}(--)\end{array}$ & $S D_{t} / X_{t-1}$ & MV \\
\hline Cardoso (1992) & (9) & $\begin{array}{l}\text { Quadrienal } \\
1970-1985\end{array}$ & $I P_{t} / Y_{t}$ & $Y_{t}^{*}(++)$ & Omitida & Omitida & $I G_{t} / Y_{t}(++)$ & IIE (-) & $D_{t} / X_{t}^{(-)}$ & MQO \\
\hline Studart (1992) & Brasil & $\begin{array}{c}\text { Anual } \\
1972-1989\end{array}$ & $I P_{t}$ & $U T C A P_{t}(+)$ & Omitida & $F_{t} \underset{(++)}{(\mathrm{BNDES})}$ & $I G_{t}(--)$ & $P_{t}(--)$ & Omitida & MQO \\
\hline $\begin{array}{l}\text { Rocha e Teixeira } \\
\text { (1996) }\end{array}$ & Brasil & $\begin{array}{c}\text { Anual } \\
1965-1990\end{array}$ & $I P_{t}$ & $\Delta Y_{t}(++)$ & $\Delta R_{t-1}$ (n.s.) & Omitida & $\Delta I G_{t-2}(-)$ & Omitida & Omitida & MCE \\
\hline $\begin{array}{c}\text { Jacinto e Ribeiro } \\
(1998)\end{array}$ & Brasil & $\begin{array}{c}\text { Anual } \\
1973-1989\end{array}$ & $\Delta I P_{t}$ & $\triangle U T C A P_{t}(++)$ & Omitida & $\Delta F_{t} \underset{(+)}{(\mathrm{BNDES})}$ & $\Delta I G_{t}(--)$ & $\Delta P_{t}(-)$ & Omitida & MQO \\
\hline $\begin{array}{l}\text { Melo e Rodrigues } \\
\text { Júnior (1998) }\end{array}$ & Brasil & $\begin{array}{c}\text { Anual } \\
1970-1995\end{array}$ & $\Delta I P_{t}$ & $\Delta Y_{t}(++)$ & $\Delta R_{t}(-)$ & Omitida & $\Delta I G_{t}(--)$ & $\Delta P_{t}(--)$ & Omitida & MCE \\
\hline $\begin{array}{c}\text { Cruz e Teixeira } \\
\text { (1999) }\end{array}$ & Brasil & 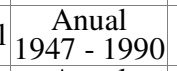 & $I P_{t}$ & $Y_{t}(+)$ & $R_{t}$ (n.s.) & Omitida & $I G_{t}(-)$ & Omitida & Omitida & MCE \\
\hline Reis et al. (1999) & Brasil & $\begin{array}{c}\text { Anual } \\
1972-1996\end{array}$ & $I P M E_{t}$ & $\begin{array}{c}U T C A P_{t-1}(++) \\
\Delta U T C A P_{t-2}^{(++)}\end{array}$ & $R_{t-1}(++)$ & Omitida & Omitida & Omitida & Omitida & MQO \\
\hline $\begin{array}{l}\text { Ribeiro e Texeira } \\
\text { (2001) }\end{array}$ & Brasil & $\begin{array}{c}\text { Anual } \\
1956-1996\end{array}$ & $\Delta I P_{t}$ & $\Delta Y_{t}(++)$ & Omitida & $\Delta F_{t}(++)$ & $\Delta I G_{t}(+)$ & $\Delta P_{t}(-)$ & $\Delta e_{t}(--)$ & MCE \\
\hline $\begin{array}{c}\text { Muinhos e Alves } \\
(2003)\end{array}$ & Bras & $1 \begin{array}{c}\text { Trimestral } \\
1995-2002\end{array}$ & $I P M E_{t} / Y_{t-1}$ & $I P M E_{t-1} / Y_{t-2}(++)$ & $R_{t-1}(--)$ & Omitida & Omitida & Omitida & Omitida & MQO \\
\hline Santos e Pires (2007) & Brasil & $\begin{array}{c}\text { Trimestral } \\
1995-2006\end{array}$ & $I P_{t}$ & $Y_{t}(+)$ & $C T_{t} / Y_{t}(-) \quad P_{K}$ & Omitida & $I G_{t}(-)$ & Omitida & Omitida & MCE \\
\hline
\end{tabular}

Fonte: Elaboração própria. 


\section{Notas da Tabela A.1}

(a) As variáveis explicativas estão ordenadas e relacionadas aos modelos teóricos correspondentes.

(b) Os sinais dos coeficientes estimados são indicados por "+" ou "-" quando estes não são estatisticamente significantes, e por “++" e "--" quando são significativos ao nível de $5 \%$.

(c) Legenda de Países:

(1) Argentina, Bolívia, Brasil, Chile, Colômbia, Costa Rica, Equador, Guatemala, Honduras, México, Nicarágua, Paraguai, Peru, Uruguai, Venezuela.

(2) Argentina, Bolívia, Brasil, Chile, Colômbia, Costa Rica, Honduras, México, Nicarágua, Panamá, Paraguai, Peru, Uruguai.

(3) Índia, Coréia do Sul.

(4) Argentina, Barbados, Bolívia, Brasil, Chile, Colômbia, Costa Rica, Dominica, Equador, Guatemala, Haiti, Honduras, Malásia, México, Panamá, Paraguai, Singapura, Sri Lanka, Tailândia, Turquia, Venezuela.

(5) Brasil, Uruguai, Venezuela.

(6) Argentina, Bolívia, Brasil, Chile, Colômbia, Costa Rica, Dominica, Guatemala, Guiana, Haiti, Honduras, Jamaica, México, Nicarágua, Panamá, Paraguai, Peru, Uruguai, Venezuela.

(7) Brasil, Colômbia, Costa Rica, Etiópia, Filipinas, Guatemala, Honduras, México, Nicarágua.

(8) Argentina, Bolívia, Brasil, Chile, Colômbia, Coréia, Costa Rica, Equador, Filipinas, Guatemala, Índia, México, Paquistão, Peru, Quênia, Singapura, Sri Lanka, Tailândia, Turquia, Uruguai, Venezuela, Zimbábue.

(9) Argentina, Brasil, Chile, Colombia, México, Venezuela.

(d) Lista de Siglas Utilizadas:

$C$ - Custo de utilização do capital.

$C T$-Carga tributária.

$D$ - Dívida externa.

$D P$ - Demanda por depósitos.

$e_{t}-$ Taxa Real de Câmbio.

$E$ - Custo de matérias-primas.

$F$ - Disponibilidade de recursos financeiros para investimento (crédito).

$I G$ - Investimento setor público.

$I I E-\ln \left(\frac{\text { Dívida }}{Y}\right)+\ln (1+P)+\ln \Delta e+\ln \Delta R$

$I P$ - Investimento setor privado.Dívida

$I P M E$ - Investimento privado em máquinas e equipamentos.

$K G$ - Estoque de capital do setor público.

$M C E$ - Modelo de correção de erro.

$M Q O$ - Mínimos quadrados ordinários.

$M Q O$ (3) - Mínimos quadrados ordinários em três estágios.

$M V$ - Máxima verossimilhança.

$P$ - Índice geral de preços (taxa de inflação).

$P^{e}-$ Taxa de inflação esperada.

$P_{K}$ - "Proxy" do preço relativo dos bens de capital (razão IPA-DI Bens de Produção/IGP-DI).

$P R$ - Prêmio de risco (volatilidade da bolsa de valores).

$Q P$ - Produção do setor privado.

$R$ - Taxa real de juros.

$R E S$ - Reservas internacionais.

$S$ - Poupança interna.

$S D$ - Serviços da dívida externa.

UTCAP - Utilização da capacidade instalada.

VMC - Volume de moeda corrente.

$X$ - Exportações.

$W$ - Salário nominal.

$Y$ - Produto interno bruto (corrente).

$Y^{T}$ - Tendência do produto.

$Y^{*}$ - Taxa de crescimento produto. 